\title{
A batalha das línguas artificiais (volapük, o primeiro ator)
}

Roberto Garvía

Tradução de Otacílio Nunes

Na noite de 18 de julho de 1831, e como uma premonição de uma vida notável, uma nova ilha, Ferdinandea, surgiu no mar Mediterrâneo, devido à atividade vulcânica. Nessa mesma noite, nasceu Johann Martin Schleyer, como ele comenta afetuosamente em sua autobiografia. Quarenta e oito anos depois, Schleyer, então um padre católico na pequena cidade de Litzelstetten, no sul da Alemanha, viveu mais uma noite memorável:

[...] de uma maneira um tanto misteriosa e mística, em uma noite escura no presbitério de Litzelstetten, perto de Constança, na sala do canto do segundo andar, de onde se tem uma vista do pátio, enquanto eu refletia vividamente sobre as loucuras, mágoas, afliçōes e infelicidades do nosso tempo, todo o edifício da minha língua internacional de repente apareceu diante de meus olhos espirituais em todo o seu esplendor. Para prestar homenagem à verdade, e deixar que ela dê seu testemunho, tenho de dizer que naquela noite de março de 1879 eu estava muito cansado; portanto, só posso proclamar com toda a gratidão e humildade que devo ao meu gênio bom todo o sistema da língua internacional volapük. Em 31 de março de 1879, comecei a compilar e anotar pela primeira vez os princípios da minha gramática (apud Haupenthal, 2005a, p. 33).

Embora ele não soubesse, nem se importasse muito quando foi informado - confiante em sua elevada proeza intelectual -, Schleyer não era o 
primeiro visionário a criar uma língua universal artificial, embora seu volapük fosse o primeiro a obter um número considerável de usuários. Entretanto, seu sucesso não permaneceu incontestado. No momento em que Schleyer decidiu aplicar seu gênio à concepção de uma língua artificial, Ludwig Zamenhof, um judeu russo discreto e mais humilde, já tinha formulado os princípios de uma nova língua, o esperanto, que poucos anos depois de sua introdução, em 1889, praticamente tomou o espaço do volapük. Em 1907, no entanto, Zamenhof experimentou uma provação muito semelhante à que ele havia impingido a Schleyer, quando Couturat, um filósofo lógico francês, desafiou o status do esperanto e lançou uma nova língua internacional: o ido. Zamenhof também ganhou essa batalha, e até o presente o esperanto continua a ser a língua artificial mais popular. No final do século XIX e no início do século XX, assim, ocorreu uma batalha de línguas artificiais. Embora essa disputa esteja hoje praticamente esquecida, a batalha das línguas artificiais e o debate sobre elas era moeda corrente na paisagem intelectual da época, quando uma fé no progresso combinada a uma demanda mais urgente para otimizar e padronizar novas melhorias tecnológicas convenceu algumas pessoas de que uma língua criada poderia servir como a língua franca de que o mundo cada vez mais interligado decididamente necessitava.

A batalha das línguas artificiais, que envolveu três principais candidatas tentando se tornar a língua auxiliar-padrão - ou a segunda língua para todos -, assemelha-se de perto a outros processos de path dependence [dependência de trajetória] que resultaram na padronização de uma tecnologia sobre sua rival, tais como o triunfo do teclado QWERTY sobre o Dvorak (cf. David, 1985), do sistema de gravação vHS sobre o Betamax (cf. Cusumano, Mylonadis e Rosenbloom, 1992), ou do sistema de abastecimento de corrente elétrica alternada sobre a corrente contínua (cf. David, 1992). Este artigo faz parte de um projeto em andamento que explora algumas questóes levantadas pela literatura de path dependence, e mais concretamente sobre o papel da liderança nas adoções de padrão.

Processos de path dependence podem ser captados pelo que os matemáticos chamam de processo de urna de Polya. Podemos imaginar uma urna que contém bolas de duas cores diferentes, vermelho e verde. Se retirarmos aleatoriamente uma bola da urna, olharmos sua cor e a devolvermos à urna acompanhada por outra bola da mesma cor, pomos em funcionamento um mecanismo de autorreforço: dado que a probabilidade de adicionar uma bola vermelha ou verde à urna é proporcional ao número de bolas vermelhas e verdes já existente, quando adicionamos uma bola verde ou vermelha, a 
probabilidade de escolher vermelho ou verde na próxima vez será afetada. Em termos matemáticos, um processo de urna de Polya indefinido não faz a proporção de bolas vermelhas na urna flutuar incessantemente e sem limite; antes, ela vai se estabilizar em um limite, que pode ser qualquer coisa entre $0 \%$ e $100 \%$.

Em processos de path dependence, os primeiros eventos (isto é, as primeiras retiradas da urna, ou as decisōes dos primeiros adotantes de usar uma tecnologia em vez da alternativa) têm um peso maior do que os últimos. Embora não necessariamente determinem o resultado final, as sequências particulares de escolha feitas nos estágios iniciais do processo, desencadeadas por pequenos eventos fortuitos, têm maior influência que escolhas posteriores - isto é, quanto mais sucesso a tecnologia $\mathrm{A}$ está obtendo, mais difícil é para $\mathrm{B}$ inverter essa situação. Em fases posteriores do processo, a mudança de uma alternativa para a outra torna-se praticamente impossível, e mecanismos de retroalimentação autorreforçadores enrijecem a estrutura da tecnologia dominante. A tecnologia vencedora, porém, não é necessariamente a melhor, ou a alternativa mais eficiente para aqueles que intervieram no processo, já que sua vitória é em grande parte o resultado de pequenos eventos fortuitos que ocorreram nas fases anteriores do processo (cf. David, 1985; Arthur, 1994, pp. 44-47). Resultados de path dependence, em suma, não são "nem seguramente eficientes, nem facilmente alterados, nem inteiramente previsíveis de antemão" (Idem, p. 25). Contudo, independentemente da aleatoriedade ou imprevisibilidade associada aos processos de path dependence, seria um erro descrevê-los como livres de agência [agency]. Como diz Douglass C. North: "A cada passo ao longo do caminho [há escolhas] - políticas e econômicas - que fornecem [...] alternativas reais. A path dependenceé uma forma de estreitar conceitualmente o conjunto de escolhas e de ligar as tomadas de decisão ao longo do tempo" (1990, pp. 98-99).

Se os processos de path dependence fossem livres de agência, deveríamos esperar que os promotores de alternativas tecnológicas assistissem passivamente ao modo como o processo se desenvolve. Mas eles não o fazem. Um processo de path dependence deixa margem para manobra, e os promotores tentarão intervir tanto quanto puderem para implementar a estratégia mais adequada em que possam pensar (cf. Cusumano, Mylonadis e Rosenbloom, 1992; Arthur, 1994, pp. 127-128). O promotor da tecnologia A, por exemplo, pode subsidiá-la reduzindo os preços abaixo dos custos de produção na esperança de que essa estratégia acabe desalojando a alternativa $B$ e torne possível capturar no devido momento recompensas decorrentes de mono- 
pólio (cf. Arthur e Ruszczynski, 1994). Da mesma forma, uma vez que os eventos iniciais têm maior peso do que os posteriores, é aconselhável de um ponto de vista estratégico entrar na competição o mais cedo possível. É igualmente conveniente disciplinar expectativas entre potenciais adotantes quanto ao que a tecnologia dominante será (cf. Arthur, 1994, p. 128).

São precisamente, como sugere David (1992, p. 134), a abertura e a possibilidade de equilíbrios múltiplos, características dos processos de path dependence, que tornam a estratégia e a liderança particularmente críticas. Tanto, de acordo com David, que a visão estratégica e o impulso interno dos líderes podem explicar em parte o resultado final de um processo de path dependence. Como ele diz:

[...] onde operam mecanismos iniciais de retroalimentação positiva localizados, aí o elemento de "acaso" ou "acidente histórico" - na forma de percepçôes pessoais idiossincráticas e predileçôes dos atores, bem como de circunstâncias estranhas e transitórias que cercam sua tomada de decisão em tais momentos - tem maior probabilidade de adquirir força suficiente para moldar os resultados finais (Idem, p. 137).

A ênfase de David na liderança, "na forma de percepções pessoais idiossincráticas e predileções dos atores", no entanto, corre o risco de explicar batalhas de padronização como uma narrativa épica, onde os heróis ou titãs estão engajados em uma disputa em que eventos inesperados simplesmente acontecem e mecanismos de autorreforço ditam caprichosamente o que ocorre a seguir. Por mais ilustrativo e fascinante que esse tipo de narrativa possa ser, ainda é possível, porém, disciplinar ou estreitar mais a interpretação de David sobre a liderança dando um passo atrás, e tentando explicar por que os líderes escolhem determinada estratégia em vez de outra, alternativa. Com esse objetivo, o conceito de "imprinting [moldagem] empresarial" (Boecker, 1988) ou "empreendedorismo cultural" (Johnson, 2007) pode ser útil.

"Imprinting empresarial" e "empreendedorismo cultural" são conceitos relacionados que sugerem que empresários ou líderes organizacionais operam com pistas que os ajudam a reduzir a incerteza e a complexidade do ambiente, entender a situação e decidir sobre uma estratégia que parece razoável. Para fazer isso, eles tomam conjuntos de modelos mentais que processam a informação e enquadram a situação em um padrão familiar que reduz o menu de opções e facilita o processo de decisão. Enquadramentos interpretativos ou modelos mentais, no entanto, não são criados ex novo a cada vez que uma 
nova situação ocorre. Ao contrário, eles são dependentes de experiências passadas (cf. Denzau e North, 1994, p. 4; Nooteboom, 2000, pp. 35-51; Bolman e Deal, 2008, pp. 3-44) e extrapolados para novos cenários ou desafios organizacionais (cf. Beckman, 2006; Boecker, 1988, 1989). O conceito de “imprinting empresarial" sugere, em resumo, que as escolhas estratégicas são dependentes de experiências e afiliações organizacionais passadas. Ou, para dizer de uma forma mais elaborada: dos recursos econômicos, tecnológicos, culturais e políticos disponíveis no ambiente no momento da fundação organizacional, a seleção daqueles que são por fim incorporados à organização e, consequentemente, terminam moldando-a de uma determinada maneira - $\mathrm{e}$ influenciando sua estratégia e desempenho futuros - depende em parte da experiência e da afiliação organizacionais passadas dos fundadores.

Em suma, e para concluir sobre a contribuição deste artigo, sugere-se aqui que o resultado de uma disputa tecnológica, onde eventos fortuitos e mecanismos de retroalimentação erodem a vantagem potencial da superioridade técnica, depende em parte das estratégias que os líderes organizacionais implementam, as quais, por seu lado, são em grande parte dependentes de sua formação e experiência organizacionais. Este artigo, portanto, põe em primeiro plano legados organizacionais, experiências passadas e filiações com o objetivo de explorar o quanto eles podem explicar os resultados de batalhas de padronização.

A batalha das línguas internacionais artificiais é um cenário privilegiado para realizar tal exploração. Primeiro, ao contrário de outras disputas tecnológicas que se desenvolveram dentro de redes complexas, entre as quais se podem incluir atores de engenharia, finanças, distribuição ou produção, a elaboração e a comercialização de uma língua artificial não envolve uma trupe tão grande, o que permite uma exploração mais direta das estratégias particulares implantadas pelos líderes organizacionais - isto é, Schleyer, Zamenhof e Couturat. Segundo, e contribuindo para esse cenário de pesquisa relativamente esterilizado, devemos ter em mente que, bem ao contrário de muitos outros cenários de padronização (cf. Mattli e Büthe, 2003), os promotores e os apoiadores estavam isolados de qualquer tipo de pressão ou interesse políticos provenientes do ambiente externo. E, por fim, a batalha das línguas artificiais envolve dois estudos de caso - a batalha do volapük contra o esperanto, no final do século XIX, e a batalha do esperanto contra o ido, nas primeiras décadas do século seguinte - e três diferentes estratégias organizacionais adotadas por líderes com experiências passadas e afiliaçōes organizacionais bastante divergentes, o que acrescenta uma variância extra à análise. 
Por razões de espaço, porém, este artigo só explorará o movimento volapük. Mais concretamente, ele tentará explicar que a estratégia implementada por Schleyer, um padre católico, pode ser explicada em grande medida por sua filiação e lealdade à Igreja Católica nos tempos da Kulturkampf, um amargo conflito que confrontou Bismarck e o papa. $\mathrm{O}$ artigo pretende mostrar que a estratégia de Schleyer assemelhava-se muito de perto à de sua organização paradigmática, a Igreja Católica, o que o impediu de fazer concessóes a outros membros de seu movimento e coordenar esforços contra o seu rival, o esperanto.

O primeiro proponente: volapük

Globalização, diglossia internacional e a demanda por uma língua artificial

Duas razões insinuam-se para explicar o sucesso do volapük. Em primeiro lugar, ele foi introduzido durante a primeira onda de globalização, momento que mudou drasticamente o tecido social e econômico das sociedades em todos os lugares, à medida que novos desenvolvimentos tecnológicos, como ferrovias, navios a vapor, o telégrafo e, mais tarde, o telefone, aboliram a tirania da distância, reduziram os custos de frete e impulsionaram o comércio internacional (cf. Bordo, Taylor e Williamson, 2003). Entre 1870 e 1913, o comércio internacional europeu em valores correntes aumentou em 294\%, uma expansão sem precedentes que se beneficiou da relativa paz entre as grandes potências europeias e da adoção do padrão ouro. A migração internacional era dinâmica. Enquanto uma média de 300 mil europeus por ano migraram para outros continentes nas três primeiras décadas da segunda metade do século XIX, seu número ultrapassou 1 milhão na virada do século (cf. O’Rourke e Williamson, 1999, p. 119; Daudin, Morys e O’Rourke, 2010).

Um mundo mais interligado trouxe novos desafios, que exigiam maior cooperação e novos organismos internacionais. Assim, em 1865 foi criada a União Telegráfica Internacional e, nove anos depois, a União Postal Universal se estabeleceu. Da mesma forma, a Conferência Internacional do Meridiano, realizada em Washington, D.C., em 1884, concordou em estabelecer coordenadas e fusos horários padronizados. Seguiram essa tendência de padronização o Bureau Internacional de Pesos e Medidas, criado em 1875, e as conferências internacionais que visavam à padronização das ferrovias. Houve iniciativas semelhantes em produtos farmacêuticos, sistemas 
bibliográficos e de catalogação, cartografia, desenho técnico, e assim por diante (cf. UAI, 1957, pp. 5-11). Certamente, a cooperação internacional nem se confinou às áreas de comunicações e comércio, nem foi defendida exclusivamente por órgãos públicos. O Comitê Internacional de Socorro aos Feridos, surgido em 1863, criou condiçōes para a fundação, em 1876, da Cruz Vermelha. Enquanto isso, em 1866, os sindicatos estabeleceram sua Primeira Internacional, e após o sucesso da Feira Mundial de Paris, em 1867, as exposições do progresso científico e tecnológico tornaram-se eventos regulares Ao todo, mais de trezentas organizaçôes internacionais floresceram nesse período (cf. Idem, ibidem), e o número de conferências internacionais cresceu de apenas vinte, na década de 1850, para 1062 , na primeira década do século xx (cf. Shenton, 1933, p. 27).

As línguas também foram afetadas por esse zelo racionalizador e padronizador. Reformas ortográficas destinadas a fazer coincidir a palavra escrita e a falada foram amplamente debatidas na França, nos Estados Unidos e na Alemanha, como meio de transcender diferenças de classe e regionais (cf. March, 1893, pp. 57-59; Staller, 1994, pp. 343-344), e no último quarto do século XIX os emergentes movimentos basco, occitano, catalão, checo e ruteno, e outros movimentos nacionalistas, começaram a padronizar suas línguas como marcadores de novas identidades políticas (cf. Hobsbawm, 1990, pp. 93-100; Balbour e Carmichael, 2000) ${ }^{1}$.

Esse impulso de racionalização, no entanto, afetou não apenas as línguas nacionais. Hoje em dia, o inglês é a língua de comunicação internacional, mas isso estava longe de ser o caso no final do século XIX. Naquela época, o cenário linguístico internacional era diglóssico (e até triglóssico). Embora o francês ainda mantivesse uma posição privilegiada na diplomacia e na política internacionais, o inglês estava ganhando terreno no comércio e o alemão prevalecia na ciência. Esse regime linguístico internacional instável e a convicção de que as rivalidades nacionais impediriam um acordo internacional que concedesse a qualquer língua nacional o status de língua franca abriram por algum tempo uma janela de oportunidade para a ideia de uma língua internacional artificial, um projeto que muitos consideravam não só adequado ou prático, mas também predestinado ao sucesso. Como disse Herbert Spencer: "é bem possível [...] que chegue o momento em que todas as línguas existentes serão reconhecidas como tão imperfeitas que haja um acordo sobre uma língua artificial a ser utilizada universalmente" (1904, vol. 1, p. 247).
1. Para uma descrição caso a caso da invenção de novas línguas nacionais, ver Fodor e Hagège (1983). 
* A data entre colchetes refere-se à edição original da obra. Ela é indicada na primeira vez que a obra é citada. Nas demais, indica-se somente a edição utilizada pelo autor [N.E.].

\section{Ameaças externas...}

Schleyer publicou o primeiro manual de volapük em alemão em 1880 . Três anos depois ele havia sido traduzido para dez línguas, e clubes locais espalharam-se pela Alemanha, Países Baixos, Suécia e Áustria (cf. Schleyer, [1880]* 1982). Essa atividade não passou despercebida, e jornais locais e estrangeiros começaram a fazer reportagens sobre o volapük, algumas com elogios copiosos, outras com escárnio. Desde o início, os volapükistas enfrentaram importantes desafios e ameaças.

Em primeiro lugar, o próprio sucesso do volapük convenceu outros, igualmente preocupados com o problema da comunicação internacional, a desenvolver as suas próprias línguas artificiais. Assim, o Weltsprache foi lançado em 1883, seguindo-se a langue international néo-latine e a pasilingua, em 1885. Nos três anos seguintes, bopal, spelin, myrana, kosmos e lingvo internacia, mais tarde chamada de esperanto, entraram na briga (cf. Couturat e Leau, [1903] 2001, pp. 262-930). Embora apenas spelin, pasilingua e lingvo internacia tenham atraído alguma atenção do público, esse desfile interminável de línguas artificiais foi, para os volapükistas, fonte não apenas de ansiedade, mas também de constrangimento. Ao tentar resolver o problema da Torre de Babel, eles pareciam ter desencadeado uma nova Babel de línguas artificiais irremediáveis, como muitas pessoas estavam mais do que felizes em apontar.

Em segundo lugar, a ideia da própria possibilidade de uma língua artificial foi recebida com muito ceticismo, em especial entre os linguistas, mais particularmente os alemães. Acompanhando a tradição romântica de Fichte, Herder e Von Humboldt, estudiosos alemães concebiam línguas como organismos vivos. De acordo com a metáfora da "língua como organismo", cada língua tem seu próprio "espírito interior”, que evolui de mãos dadas com o gênio ou Geist da nação. Língua e nação são, assim, duas diferentes manifestações do mesmo fenômeno, emergindo do Volkgeist. Desse ponto de vista, as línguas estão envolvidas em uma luta interminável pela sobrevivência. Elas podem conquistar ou ser conquistadas, podem morrer e desaparecer sem deixar vestígio, ou deixar atrás de si uma prole saudável na forma de novas línguas, mas nunca podem ser aprioristicamente inventadas (cf. Formigari, 2004, pp. 144-146). Para a maioria dos linguistas alemães, o conceito de uma língua universal seria um oxímoro. Como a língua de todos, uma língua universal seria a língua de ninguém: um corpo sem sangue nas veias, um "homúnculo", para usar a palavra da moda coetânea. Embora 
essa negação da própria possibilidade de uma língua artificial, por sua vez, enfrentasse refutação (por exemplo, Schuchardt, 1888, 1894), o ataque lançado pelos Herren Linguistik Professoren (cf. Müller, 1888; Ziemer, 1888; Meyer, [1893] 1976) machucou os volapükistas e sua reputação.

Em terceiro lugar, o rápido sucesso do volapük também chamou a atenção da Sociedade Filosófica Americana. Embora essa sociedade estivesse convencida de que uma língua artificial era não apenas possível, mas também necessária para a comunicação internacional, ela ainda pensava ser imperativo verificar se o volapük cumpria os requisitos mínimos para servir a esse propósito, e para tanto criou uma comissão especial para estudar essa questão. O relatório da comissão, publicado em 1888, tinha conclusões devastadoras. $\mathrm{O}$ volapük foi considerado excessivamente inflexional e seu vocabulário, irreconhecível e inadequado para a comunicação internacional. Segundo a Sociedade Filosófica Americana, uma língua artificial devia ter uma gramática não inflexional, semelhante à do inglês ou da maioria das línguas românicas, bem como um "léxico ariano" reconhecível - isto é, um vocabulário derivado naturalmente das raízes das línguas indo-europeias. A Sociedade também sustentava que uma língua artificial não deveria ser o trabalho de uma única pessoa, mas criada e lançada da mesma maneira que a maioria dos padrões internacionais o tinha sido no passado. Para isso, convidou outras sociedades cultas a juntar-se e criar uma comissão internacional (cf. American Philosophical Society, 1888, 1889).

A Sociedade Filológica de Londres, no entanto, tinha uma opinião diferente. Achava que, apesar de não ser perfeito, o volapük era bom o suficiente para servir como uma língua auxiliar. Para grande desgosto dos volapükistas, porém, a sociedade de Londres considerava o spelin melhor, tanto que, se tivesse sido lançado primeiro, o spelin teria sido "muito mais amplamente aceito, e tornado-se, como o seu nome sugere, a língua de todos" (cf. Ellis, 1888, pp. 90-91). Por conseguinte, e embora a Sociedade Filológica de Londres concluísse seu relatório com um sonante "Longa vida ao volapük", isso se devia menos às suas qualidades inerentes, como sua relativa vantagem sobre o spelin em termos de dinâmica positiva de rede: uma vez que o volapük tinha "o ouvido do público e está na posse de uma vasta organização extremamente interessada em propagá-lo”, a conveniência aconselhava o apoio (cf. Idem, p. 97). A Sociedade Filológica, em suma, tinha servido para contrariar as conclusões dos norte-americanos, mas por razões que os volapükistas não estavam ansiosos para ouvir. Contudo, como veremos imediatamente, a verdadeira ameaça ao volapük não veio de fora das sociedades científicas, mas de dentro. 


\section{... e contestações internas: o problema da coordenação}

Ainda imperturbados pelas contestações vindas do meio ambiente, em 1884, os volapükistas realizaram seu primeiro congresso, que aprovou a criação de um periódico oficial, o Volapükabled zenodik, que publicaria os nomes dos indicados para ocupar cargos no movimento. E também aprovou um primeiro relato detalhado de sua hierarquia formal. No alto desta estava Schleyer, que havia se tornado líder perpétuo e obtido poder de veto sobre todas as decisões organizacionais e linguísticas (cf. Haupenthal, 1984, p. 88). O segundo congresso, também realizado no sul da Alemanha, ocorreu três anos depois. Para garantir a integridade da língua, e seguindo o exemplo da Académie Française, foi aprovada a criação de uma Academia Volapükista. Esse congresso testemunhou os primeiros sinais de desacordo interno. Enquanto Schleyer e volapükistas conservadores tomavam as ameaças vindas do exterior como evidência da necessidade de se unir em torno da linguagem tal como ela era, outros volapükistas, liderados pelo francês Auguste Kerckhoffs, argumentavam que as críticas externas aumentavam a urgência da tarefa de introduzir na língua as reformas necessárias. As reformas preconizadas por Kerckhoffs (1887) iam na direção de simplificar a gramática e o léxico da língua. Mas suas ideias estavam em conflito com as de Schleyer, convencido de que a complexidade da sua língua, que permitia a expressão das menores nuances e sutilezas da cognição humana, era mais uma vantagem do que um obstáculo.

Esses pontos de vista opostos entraram em confronto em 1888, um ano antes do terceiro congresso, quando uma batalha aberta em Munique entre os reformistas locais e os conservadores levou a uma cisão e ao surgimento de duas associações de volapük concorrentes na cidade. Ainda mais ameaçadora para o futuro do movimento foi a decisão do clube de volapük de Nuremberg de aderir a um novo projeto, o lingvo internacia, mais tarde chamado de esperanto (cf. Kniele, [1889] 1989, p. 77; Schmidt, [1964] 1986, pp. 16-17). Com medo de perder o controle e para organizar o próximo congresso, Schleyer convocou seus seguidores em maio de 1888. A conclusão dessa reunião, imediatamente publicada no periódico oficial, Volapükabled zenodik, foi um ipse dixit direto: "Qualquer resolução da Academia que não tiver sido aceita pelo Inventor é nula, mesmo que toda a sociedade tenha se unido contra o Inventor" (Ellis, 1888, p. 66; Barandovská-Frank, 2002, p. 6).

Os delegados ao terceiro congresso, realizado em agosto de 1889, tinham uma tarefa difícil. Precisaram pôr de lado suas diferenças e evitar uma colisão 
direta entre reformistas e conservadores. Para satisfazer ambas as partes, os delegados concordaram em alterar os estatutos da Academia. $\mathrm{O}$ acordo era que cada resolução tomada pela Academia sobre questôes de língua devia ser submetida à aprovação de Schleyer. Se isso não fosse iminente, haveria mais discussão e uma segunda votação pela Academia. Se ela obtivesse dois terços dos votos, o veto de Schleyer seria derrubado. Esse acordo permitiu que Schleyer mantivesse sua posição como o membro mais poderoso do movimento, embora seu poder de veto fosse diluído (cf. Sprague, 1889), o que era inaceitável para ele. Ele reivindicou o volapük como sua propriedade intelectual, rejeitou formalmente a autoridade da Academia e criou uma nova, que foi confinada a seus apoiadores mais fiéis. Logo após o congresso, Schleyer e os reformistas se separaram (cf. Rosenberg, 1903, pp. 277-282).

Livre do domínio de Schleyer, Kerckhoffs pôs a Academia para trabalhar velozmente a fim de reformar a língua e impedir que outros projetos, em especial o esperanto, ganhassem terreno. Imediatamente após o congresso, ele enviou sua proposta de reforma a membros da Academia, pedindo-lhes que o discutissem com as sociedades dos países que representavam. Em vez de uma resposta clara, ele recebeu outras nove propostas de reforma. Cansado, renunciou. Durante os três anos seguintes, a Academia permaneceu ociosa, já que seus membros não conseguiram chegar a um acordo sobre um novo diretor. Quando Woldemar Rosenberg, o líder do movimento em Moscou, foi nomeado, ele imediatamente alterou o processo de tomada de decisão da Academia, permitindo que seus membros votassem sem consulta prévia aos volapükistas da base. Esse movimento privou os apoiadores de base de qualquer influência sobre a forma final da língua, o que gerou uma onda de deserçôes. Eles haviam se oferecido para aprender, ensinar e expandir uma língua artificial, mas não havia muito a fazer se tal língua permanecesse em construção e eles não fossem perguntados sobre sua orientação futura. Alguns voltaram a aliar-se a Schleyer e outros passaram a apoiar o esperanto, mas a maioria simplesmente desistiu. Para Schleyer, a saída de Kerckhoffs e dos reformistas como ele foi um alívio; tomou isso como uma oportunidade de expurgar a organização e fortalecer sua musculatura, de acordo com os rigorosos princípios hierárquicos impostos por ele em seu início. O expurgo foi alcançado com facilidade - ele simplesmente eliminou os nomes dos criadores de problemas da lista de volapükistas publicada no periódico oficial. Como explicou claramente, não podia conceber nenhum curso de ação diferente: "O cristianismo é melhor do que a minha descoberta, e lá também houve conflitos. Os apóstolos disputaram sobre quem entre eles 
era o mais qualificado. E então veio Jesus, que resolveu a briga" (Rund um die Welt, 16 de dezembro de 1890, pp. 283-284).

Schleyer se pôs a aperfeiçoar a estrutura piramidal da organização com uma distribuição mais detalhada dos privilégios e das responsabilidades de cada nível hierárquico. No degrau mais baixo ficavam os estudantes, ou $j u$ lans, que poderiam corresponder-se com outros volapükistas (como spodels) e/ou participar informalmente de um clube local (como kopanels). Pertencimento pleno ao movimento, no entanto, só poderia ser obtido ganhando um diploma na língua. Volapükistas graduados poderiam corresponder-se com outros membros (como spodals) e competir por posiçōes de liderança em seus clubes em sua nova capacidade de kopanals. No degrau acima dos líderes de clube (cifs) ficavam os líderes regionais ou nacionais (cifels) e líderes de nível federal (lecifs). Uma hierarquia semelhante foi estabelecida para professores da língua, incluindo instrutores de clube (tidels), instrutores de cidade (löpitidels) e "professores" em nível nacional, ou plofeds. Os representantes responsáveis por conceder os certificados de ensino eram os xamels, que operavam em nível nacional. Em uma posição mais elevada ficavam os kademals, ou membros da Academia de Schleyer. Ainda mais acima na escala hierárquica estavam os senatäns, ou senadores, um pequeno corpo de conselheiros pessoais de Schleyer, nomeados a critério dele. Finalmente, na sua condição de cifal, ou líder permanente e supremo do movimento, Schleyer poderia revogar qualquer nomeação feita por clubes e organizações, não as ratificando no Volapükabled zenodik, onde Schleyer publicava suas decisões compulsórias ou "editais" (cf. Kniele, 1989, pp. 71-73). Contudo, a iniciativa de Schleyer não conseguiu frear o declínio do movimento. Em 1894, apenas cinquenta associações locais permaneciam ativas, das 250 que haviam florescido cinco anos antes, e em 1905 somente nove ainda estavam em funcionamento. As duas últimas foram dissolvidas quatro anos depois, e na virada do século o volapük estava praticamente morto (cf. Schmidt, 1986, pp. 28, 34-35).

De uma perspectiva histórica, o volapük tinha a vantagem do incumbente na batalha das línguas artificiais. Em pouco tempo ele tinha conseguido incitar o entusiasmo de numerosas pessoas instruídas que estavam dispostas a suportar críticas e até mesmo zombaria, e que acreditavam firmemente que a língua internacional definitiva havia chegado. Ainda assim os volapükistas fracassaram. Em vez de explorar a sua posição como incumbentes, eles a desperdiçaram. Reformistas e conservadores haviam jogado um jogo de coordenação clássico, e mesmo quando ambos poderiam ter se beneficiado 
de um acordo mútuo, este revelou-se impossível de ser atingido. Contemporâneos culparam Schleyer por esse fracasso, e provavelmente com razão. Ele exercia grande poder no movimento e poderia forçar a reconsideração de qualquer proposta de reforma, mas isso não foi o suficiente para ele. Nada menos do que o controle absoluto poderia satisfazê-lo.

Schleyer certamente poderia ter agido de maneira diferente e intermediado um compromisso satisfatório. Então, por que ele preferiu pôr em risco todo o seu projeto? Duas explicaçōes possíveis podem ser aventadas. A primeira está enraizada em sua autoestima, seu apego à sua língua, e no que o volapük significava para ele. Isso entrava em contradição direta com a posição de Kerckhoffs. Enquanto este via o volapük em termos estritamente utilitários, Schleyer enfatizava sua dimensão estética (cf. Staller, 1994, p. 341). Ele havia conquistado alguma reputação como poeta, e como tal estava particularmente inclinado a fazer experimentos com a língua, a esticar e distorcer seus limites. Ele se via como um artista que trabalhava com palavras. Artistas não negociam cores ou materiais, nem deixam que uma assembleia democrática tome decisões sobre questões estéticas. $\mathrm{O}$ volapük era para ser admirado ou imitado, mas apenas Schleyer tinha o direito de torná-lo mais gracioso ou mais belo. Era a sua obra-prima, sob necessidade constante de proteção. Como ele disse: "O volapük é o meu filho problemático, meu filho carente, meu filho intimidado" (Rund um die Welt, 16 de dezembro de 1890, pp. 283-284). E foi a esse clichê do artista como alguém apaixonado, imaturo e infantil que seu superior, o arcebispo de Freiburg, recorreu no obituário de Schleyer:

Para quem conhecia superficialmente Schleyer, era difícil, ao se aproximar dele, não ser surpreendido pela efervescência de sua personalidade. [...] Schleyer era de muitas maneiras, e até mesmo em sua velhice, uma criança. Era a sua infantilidade que o fazia falar tantas vezes e de modo autocongratulatório sobre si mesmo [...]. Qualquer pessoa que o visitasse em seu estúdio podia ler em seu rosto quão feliz sua visita o fazia, e ninguém podia sair sem levar nas mãos um pequeno pacote de amostras literárias do inventor da língua mundial. Feliz como uma criança! (apud Haupenthal, 2007, p. 28)

O foco na personalidade peculiar de Schleyer nos levaria ao tipo de narrativa épica a que David recorre em seu relato da batalha entre Edison e Westinghouse. Uma segunda explicação, provavelmente mais satisfatória, do fracasso do volapük aponta para a filiação de Schleyer à Igreja Católica 
e para sua experiência na Kulturkampf como a fonte do éthos autoritário distintivo que ele imprimiu a seu movimento, e que moldou suas estratégias contra os reformistas.

\section{Imprinting organizacional: o legado da Kulturkampf}

Imediatamente após a unificação da Alemanha, em 1871, o primeiro chanceler do país, Otto von Bismarck, iniciou uma campanha política destinada a ganhar a lealdade incondicional dos católicos alemães. Essa campanha, que seus contemporâneos mais tarde apelidariam de Kulturkampf, ou cultura de guerra, foi uma reação ao Syllabus de 1864 do papa Pio IX, que condenava o liberalismo, o livre-pensamento, a ciência moderna, a educação secular, o casamento civil e qualquer interferência do Estado nos assuntos da Igreja, depois cimentado pelo dogma da infalibilidade papal. Na atmosfera muito acalorada da Kulturkampf, a posição de Bismarck não foi menos apaixonada do que a do papa, e encontrou expressão na expulsão das ordens jesuítas, franciscanas e dominicanas, na afirmação do direito de nomear e demitir o clero católico, na apreensão de bens da Igreja e no fim da supervisão das escolas por membros da Igreja. As leis anticatólicas de Bismarck, que o papa declarou nulas e sem efeito (cf. Coppa, 1979, pp. 140-168, 189), levaram à prisão ou ao exílio de todos os bispos da Prússia em 1876, e, quando a Kulturkampfterminou, cerca de 1800 sacerdotes católicos em toda a Alemanha haviam sido multados ou presos (cf. Gross, 2004, pp. 246-258). Um deles foi Schleyer.

Por mais amarga que fosse, a luta de Pio IX com o novo Estado alemão significou apenas um acontecimento secundário em comparação com sua campanha contra o inimigo interno: o movimento Católico Antigo, cujos membros desafiadoramente rejeitavam não só os ensinamentos do papa, mas toda a estrutura organizacional da Igreja, que queriam substituir por um modelo baseado no episcopado diocesano, considerado mais de acordo com as tradiçôes do cristianismo primitivo. Enquanto liberais católicos procuravam desesperadamente uma posição mais conciliatória que os pouparia de ter de escolher entre a Igreja e o Estado (cf. Mergel, 1996), os Católicos Antigos eram veementes em sua animosidade contra o papa. Apesar de não serem fortes em termos numéricos, suas crenças fervorosas e o apoio de Bismarck os colocou na vanguarda da Kulturkampf (cf. Gröber, 1912; Gross, 2004, pp. 253-254). O apoio deles a Bismarck lhes valeu duras penas de Roma. Alguns de seus líderes foram excomungados (cf. Scarth, 1883, pp. 31-40) e padres fiéis a Roma receberam ordem de recusar os sacramentos aos Católicos Anti- 
gos (cf. Mullinger, 1875, pp. 93-136; Scarth, 1883, pp. 31-40, 129; Coppa, 1979, p. 189).

Como jovem sacerdote, Schleyer desempenhou um papel ativo nesse confronto e, na verdade, foi sua recusa a dar um enterro apropriado a um Católico Antigo que o levou à prisão (cf. Haupenthal, 2007, p. 10). Durante a Kulturkampf, Schleyer posicionou-se entre os leais à Igreja, e interpretou seu confronto com os reformistas do volapük como uma reencenação de sua velha luta contra os Católicos Antigos, uma nova batalha na guerra entre a Verdade revelada e seus inimigos. Para começar, ele forjou uma organização que se assemelhava muito à própria Igreja, com uma hierarquia rígida, que incluía um Senado, análoga à prelazia romana, cujos membros eram selecionados com base na lealdade pessoal (cf. Haupenthal, 1984, p. 105). Como Pio Ix, ele afirmou sua própria infalibilidade em todos os assuntos, fossem organizacionais, fossem linguísticos, e quando os reformistas desafiaram sua autoridade ele os "excomungou", arrancando seus nomes do periódico oficial do volapük. Como o papa, Schleyer exigia lealdade inabalável. Críticas, mesmo do tipo construtivo, estavam fora de questão, e qualquer um que procurasse contribuir com ideias para o movimento era mandado embora. $\mathrm{O}$ volapük, Schleyer insinuava, viera a ele como uma espécie de revelação, e assim como o papa era o vigário de Cristo na Terra, ele era o cifal no movimento.

\section{Conclusão}

O primeiro proponente na batalha das línguas internacionais não foi capaz de colher os benefícios do incumbente. O imprinting organizacional do movimento, explicado pelos modelos mentais, pelas experiências e filiação passadas de Schleyer, mostrou-se inadequado para a tarefa a executar. A estratégia autoritária de Schleyer não ajudou a resolver o problema de coordenação que o movimento enfrentou. $\mathrm{O}$ movimento volapük falhou em produzir uma versão padronizada da língua - uma questão de vida ou morte em qualquer batalha na qual operam mecanismos de retornos positivos crescentes. Zamenhof, o promotor do esperanto, administrou o golpe de misericórdia. Ele era mais talhado para a tarefa. Seu envolvimento político anterior no movimento pré-sionista na Europa Oriental permitiu que imprimisse ao movimento esperantista um equilíbrio melhor entre vocalização e lealdade - lealdade, nesse caso, não a ele, mas ao ideal político de uma língua internacional destinada a erodir sentimentos nacionalistas 
e promover a cooperação internacional. Seu movimento teve, contudo, de enfrentar um desafio difícil, quando um ex-esperantista, Couturat, um dos fundadores da lógica simbólica moderna, apareceu com um esquema de língua presumivelmente melhor e criou um movimento de fragmentação moldado na cultura organizacional e nas estratégias do mundo acadêmico. Mas essa história tem de esperar. À medida que ela se desenvolve, a esperança é mostrar, no futuro, que a batalha das línguas artificiais pode informar-nos sobre o impacto da liderança e do imprinting empresarial em processos de path dependence.

\section{Referências Bibliográficas}

American Philosophical Society. (1888), "Report of the Committe appointed Oct. 21,1887 , to examine into the scientific value of the Volapük". Nature, 38: 351-355. (1889), "Ergänzungs-Bericht des Comitè zur Formulierung einer international Sprache erstatet von demselben ... am 7. Dezember 1888”. In: Einstein, Leopold. Weltsprachliche Zeit- und Streitfragen. Nuremberg, Stein, pp. 21-26.

ARTHUR, W. Brian. (1994), Increasing returns and path dependence in the economy. Ann Arbor, University of Michigan Press.

ARTHUR, W. Brian \& RuszczYNSKI, Andrzej. (1994), "Strategic pricing in markets with increasing returns". In: ARTHUR, W. Brian. Increasing returns and path dependence in the economy. Ann Arbor, University of Michigan Press, pp. 159-201.

Balbour, Stephen \& Carmichael, Cathie (orgs.). (2000), Language and nationalism in Europe. Oxford, Oxford University Press.

Barandovská-Frank, Vera. (2002), "Über die Academia pro Interlingua". In: BlanKE, Detlev (org.). Plansprachen und ihre Gemeinschaften. Berlim, Gesellschaft für Interlinguistik e. V., pp. 13-21.

BAUER, Georg. (1888), Spelin eine Allsprache. Zagreb.

BECKMAN, Christine M. (2006), "The influence of founding team company affiliations on firm behavior”. Academy of Management Journal, 49: 741-758.

BOECKER, Warren. (1988), “Organizational origins: entrepreneurial and environmental imprinting at the time of founding”. In: Carroll, Glenn R. (org.). Ecological models of organizations. Cambridge, Mass., Cambridge University Press, pp. 33-51. . (1989), "Strategic change: the effects of founding and history". Academic Management Journal, 32: 489-515.

Bolman, Lee G. \& Deal, Terrence E. (2008), Reframing organizations: artistry, choice, and leadership. San Francisco, John Wiley and Sons. 
Bordo, Michael D., Taylor, Alan M. \& Williamson, Jeffrey G. (orgs.). (2003), Globalization in historical perspective. Chicago, Chicago University Press.

Brugmann, Karl \& Leskien, Ausgust. (1907), Zur Kritik der künstlichen Weltsprachen. Strasbourg, Karl J. Trübner.

Coppa, Frank J. (1979), Pope Pius IX: crusader in a secular age. Boston, Twayne.

Couturat, Louis \& LEAU, Léopold. (2001), Histoire de la langue universelle. Organizado por Reinhard Haupenthal. $1^{a}$ edição 1903. Hildesheim, Georg Olms.

Cusumano, Michael A., Mylonadis, Yiorgos \& Rosenbloom, Richard S. (1992), "Strategic maneureving and mass-market dynamics: the triumph of vHS over Beta". Business History Review, 66: 51-94.

Daudin, Guillaume, Morys, Matthias \& O'Rourke, Kevin H. (2010), “Globalization, 1870-1914”. In: Broadberry, Stephen N. \& O’Rourke, Kevin H. (orgs.). The Cambridge economic history of modern Europe. Vol. 2: 1870 to the present. Cambridge, Cambridge University Press, pp. 5-29.

David, Paul A. (1985), "Clio and the economics of QWERTY". American Economic Review, 75: 332-337.

(1992), "Heroes, herds and hysteresis in technological history: Thomas Edison and 'The battle of the systems' reconsidered". Industrial and Corporate Change, 1: pp. 129-176.

De Courtenay, Jan Baudouin. (1976), “Zur Kritik der künstlichen Weltsprachen”. In: Haupenthal, Reinhard (org.). Plansprachen. Beiträge zur Interlinguistik. $1^{\text {a }}$ edição 1907. Darmstadt, Wissenschaftliche Buchgesellschaft, pp. 59-110.

Denzau, Arthur T. \& NorTh, Douglass C. (1994), "Shared mental models: ideologies and institutions". Kyklos, 47: 3-31.

ElLIS, Alexander J. (1888), "On the conditions of a universal language". Transactions of the Philological Society. Grã-Bretanha, Philological Society, pp. 59-98.

FODOR, Istvan \& HAGÈGE, Claude (orgs.). (1983), Language reform: history and future. Hamburgo, Buske, 3 vols.

Formigari, Lia. (2004), A history of language philosophies. Amsterdã, John Benjamin. GrÖBER, Konrad. (1912), "Der Altkatholizismus in Messkirch. Die Geshichte seiner Entwiklung und Bekämpfung”. Freiburger Diozesan-Archiv, 40: 135-198.

Gross, Michael. (2004), The war against catholicism. Ann Arbor, University of Michigan Press.

Hamel, Richard. (1889), Die reaktionäre Tendenz der weltsprachlichen Bewegung, nebst über Untersuchungen über Wessen und Entwicklung der Sprache. Halle a/S., Tausch \& Grosse.

Haupenthal, Reinhard. (1984), Der erste Volapük-Kongress. Friedrichshafen, August 1884. Saarbrücken, Iltis. 
. (1989), "Nachwort zum Neudruck". In: KNIELE, Rupert. Der erste Jahrzehnt der Weltsprache Volapük. $1^{a}$ edição 1889. Saarbrücken, Iltis, pp. 133-142. . (2005a), Über die Startbedingungen zweir Plansprache. Saarbrücken, Iltis. . (2005b), 125 Jahre Volapük. Leben und Werk Johann Martin Schleyer (18311912). Saarbrücken, Iltis.

- (2005c), La pastro de Litzelstetten. Decenio (1875-1885) en la vivo de Johann Martin Schleyer (1831-1912). Saarbrücken, Iltis. . (2007), Prälat Johann Martin Schleyer (1831-1912). Saarbrücken, Iltis.

Hoвsваwм, Eric. (1990), Nations and nationalism. Cambridge, Cambridge University Press.

Holmes, Michael A. F. (1903), Dictionary of the neutral language. Rochester, NY, John P. Smith.

JoHnson, Victoria. (2007), "What is organizational imprinting? Cultural entrepreneurship in the founding of the Paris Opera”. American Journal of Sociology, 113: 97-127.

KeRCKHOFFS, Auguste. (1887), Langue commercial internationals: cours complet de Volapük. 8 ed. Paris, Le Soudier.

KNIELE, Rupert. (1989), Der erste Jahrzehnt der Weltsprache Volapük. 1a edição 1889. Saarbrücken, Iltis.

Löw, Heinrich. (1891), "Christian Karl Gross. Ein Gedenkblatt”. Rund um die Welt, 30 set.-16 out., pp. 193-196.

March, Francis A. (1893), “The spelling reform”. Bureau of Education. Circular of Information, n. 8. Washington D.C., Government Printing Office.

MatTli, Walter \& BüTHe, Tim. (2003), “Setting international standards: technological rationality or primacy of power?”. World Politics, 56: 1-42.

Mergel, Thomas. (1996), "Ultramontanism, liberalism, moderation: political mentalities and political behavior of the German catholic Bürgertum, 1848-1914". Central European History, 29: 151-174.

Meyer, Gustav. (1976), "Weltsprache und Weltsprachen”. In: HaupentHaL, Reinhard (org.). Plansprachen-Beiträge zur Interlinguistik. 1a edição 1893. Darmstadt, Wissenschaftliche Bushgesselschaft, pp. 28-45.

Müller, Ernst. (1888), Der Phantom der Weltsprache. Worte der Aufklärung und Ernüchterung über das Volapük und den Weltsprach-Gedanken im Allgemeinen. Berlim, Ulrich.

MULLINGER, J. B. (1875), The new reformation: a narrative of the old catholic movement from 1870 to the present time. Londres, Longmans.

Nоотевоом, Bart. (2000), Learning and innovations in organizations and economies. Oxford, Oxford University Press. 
NORTH, Douglass C. (1990), Institutions, institutional change, and economic performance. Cambridge, Cambridge University Press.

O’Rourke, Kevin H. \& Williamson, Jeffrey G. (1999), Globalization and history. Cambridge, Mass., MIT Press.

RosenberG, Woldemar. (1903), "Brief history of the International Academy of the Universal Language”. In: Holmes, Michael A. F. Dictionary of the neutral language. Rochester, NY, John P. Smith, pp. 277-300.

SCARTH, A. M. E. (1883), The story of the old catholic and kindred movements. Londres, Simpkin.

SCHLEYER, Johann Martin. (1885), Hauptgedanken meiner öffentlichen Vortrage über die von mir ersonnene Allsprache Volapük. Konstanz, A. Moriell. (1888), "Wie kam der Erfinder del Weltsprache Zur Idee seiner Erfindung?”. Rund um die Welt, 30 mar., pp. 1-4, e 14 abr., pp. 17-19. (1912), Ein Idealvolk. 2 ed. Constanz, Weltsprache. (1982), Volapük. Die Weltsprache. Entwurf einer Universalsprache für alle Gebildete der ganzen Welt. Organizado por Reinhard Haupenthal. 1ª edição 1880. Hildesheim, Olms. . (2008), “Meine Biographie”. In: Haupenthal, Reinhard (org.). Prälat Johann Martin Schleyer (1831-1912). 1a edição 1880. Saarbrücken, Iltis, pp. 121-146. ScHмidT, Johann. (1986), Geschichte der universalsprache Volapük. Organizado por Reinhard Haupenthal. $1^{a}$ edição 1964. Saarbrucken, Iltis.

Schuchardt, Hugo. (1888), Auf Anlass des Volapüks. Berlim, Robert Oppenheim. (1894), Weltsprache und Weltsprachen, an Gustav Meyer. Strassburg, Karl J. Trübner (http://schuchardt.uni-graz.at, consultado em 24 de maio de 2010). Shenton, Herbert N. (1933), Cosmopolitan Conversation. Nova York, Columbia University Press.

Spencer, Herbert. (1904), An autobiography. Nova York, Appleton and Cia., 2 vols. Spielmann, Sigmund (org.). (1887), Volapük-Almanach für 1888. Leipzig, Mayer. Sprague, Charles E. (1889), “The Volapük Congress at Paris”. Volapük. A Monthly Journal of the World Language, pp. 40-46.

STALLER, Natasha. (1994), "Babel: hermetic languages, universal languages, and anti-languages in fin de siècle Parisian culture”. Art Bulletin, 76: 331-354.

UAI (Union of International Associations). (1957), Les 1978 organisations internationales fondées depuis le Congrès de Vienne. Bruxelas.

Ziemer, H. (1888), “E. Müller. Das Phantom der Weltsprache”. Berliner Philologische Wochenschrift, 47: 1458-1459. 


\section{Resumo}

A batalha das línguas artificiais (volapük, o primeiro ator)

Este artigo faz parte de um projeto de pesquisa em andamento sobre a batalha das línguas artificiais (volapük, esperanto e ido) que ocorreu na virada do século Xx, quando a ausência de uma língua franca e as demandas de um mundo mais globalizado fizeram algumas pessoas acreditar que uma língua artificial podia ser a solução para a dificuldade de comunicação do mundo. $\mathrm{O}$ artigo baseia-se nas literaturas sobre padronização e path dependence [dependência de trajetória], e destaca a necessidade de se concentrar na liderança e no imprinting [moldagem] empresarial para entender melhor os processos de path dependence e os resultados da padronização. Por razões de espaço, porém, este artigo se concentra apenas no primeiro proponente: o volapük.

Palavras-chave: Path dependence; Volapük; Língua franca; Esperanto.

\section{Abstract}

The battle of the artificial languages (volapük, the first mover)

This article is part of an ongoing research project on the battle of artificial languages (Volapük, Esperanto and Ido) that took place at the start of the twentieth century, when the absence of a lingua franca and the demands of a more globalized world made some people believe that an artificial language could be the solution to the world's communication problemas. The article sets out from the literature on standardization and path dependence, emphasizing the need to focus on leadership and entrepreneurial imprinting to gain a beteer understanding of path dependence processes and standardization outcomes. For space reasons, though, this article only concentrates on the first mover: Volapük.

Keywords: Path dependence; Volapük; Lingua franca; Esperanto.

Texto recebido em $1 / 8 / 2012$ e aprovado em $6 / 8 / 2012$.

Roberto Garvía é professor de sociologia e participa do Grupo de Sociologia Comparada da Universidade Carlos III de Madri. E-mail: <roberto.garvia@ uc3m.es>. 